\title{
A LABORATORY MODEL FOR THE ADSORPTION AND LOSS OF THE SULFATE TRANSPORT IN MULTI POROUS MEDIA OF SOIL
}

\author{
${ }^{*}$ Najeeb Alnsrawy ${ }^{1}$
}

\author{
Sadiq S. Muhsun²
}

\author{
Zainab T. Al-Sharify ${ }^{1}$
}

1) Environmental Engineering Department, College of Engineering, Mustansiriyah University, Baghdad, Iraq

2) Department of Water Resources Engineering, College of Engineering, Mustansiriyah University, Baghdad, Iraq

\begin{abstract}
Development of industries and agriculture, salts, especially sulfates, used in many industries, such as fertilizers and pesticides, have become one of the most common problems. In this paper, a laboratory model was established to study the sulfate-contaminated transport process. Four samples of porous media contain the same pollutant, sandy soil, sandy gravel soil, agricultural (organic) soil, and calcareous soil. Where a pollutant is pumped at a concentration of $280 \mathrm{mg} / \mathrm{l}$ through a system consisting of a tube of length 4 meters and $8 \mathrm{~cm}$ thickness and distributed in the soil Each type is one meter. The results showed that all types of soils, except organic, had leaching or loss of sulfates from the soil and dissolving them with a soil solution. The transfer of pollutants from soil to the solution may reach between 50 to $300 \mathrm{mg} / \mathrm{l}$ per meter, while organic soil showed the ability to Absorption up to $100 \mathrm{mg} / \mathrm{L}$ per meter. However, it was found that organic soil contains the largest amount of sulfate and was able to adsorption, and it was found that bacterial activity has a role in reducing sulfate in organic soil and thus returning the soil to adsorption after a certain time of saturation process.
\end{abstract}

Keywords: porous media, Soil contaminant transmit sulfate transport, adsorption.

\section{Introduction}

Recent times, the problem of soil and groundwater pollution has become a major and common geo-environmental problem.Soil pollution occurring in a particular area can contain several different types of pollution or pollutants with a significant impact on the soil. The disposal of pollutants or uncontrolled wastes is considered a dangerous source of soil, surface water, and groundwater pollution. Researchers in this field have conducted many experiments and studies where every polluted site has its characteristics, and also pollution can be characterized by many forms and varies according to the nature of the site $[1,2]$. In the past two decades, the element of sulfur has been identified as a decrease or increase in it as an obstacle to crop production in various parts of the world [3-5]. One of the main reasons that led to an increase in the element of sulfur are emissions of sulfur oxides from power plants and various industrial sources, the use of sulfur in agricultural fertilizers, fungicides, and pesticides [1, 3]. Sulfur in the soil is in two forms, either organic or inorganic, and sulfur is cycled between these two forms through the processes of oxidation, reduction, mobilization and mineralization, and imobili- zation. Organic sulfur compounds are largely immobile while inorganic compounds are more mobile and that sulfates $\left(\mathrm{SO}_{4}{ }^{-2}\right)$ are more a sulfur compound has mobility, and the kinetics of sulfate is affected by the adsorption that takes place from the soil particles. This naturally depends on the concentration of a solution in the soil, the type of soil, the $\mathrm{pH}$, and other ions in the 
solution [6]. Sulfates are considered the most important source for plants and their percentage of sulfur content is estimated at approximately $5 \%$ in the soil. It can be divided into two parts: one part $\mathrm{SO}_{4}{ }^{2}$ adsorbed by the soil and the second part $\mathrm{SO}_{4}^{2}$ in the soil solution [7].

The main objective of this research is to study the process of transporting pollutants through the multiple and different porous media of soil containing the same pollutant, and to know the process of adsorption or dissolution of the pollutant within a specific distance.

\subsection{Mobility of Sulfate}

The process of washing out sulfates or losses depends mainly on the ability of the soil to retain sulfate. Soils with a fine texture have fewer losses than soils with a coarse texture. This is because the soft soil has the flow of the solution at a lower rate of movement than the coarse soil and thus the rate of preservation of sulfate is higher[8-9]. When using agricultural fertilizers in the soil, the amount of sulfate that is transferred depends on the shape, timing, and rate of application of the fertilizer. Applying large quantities of fertilizers containing sulfates in combination with a certain amount of water results in a greater amount of sulfates that can be transported through the soil column [10].

Studies have proven that time directly affects the retention/transfer process between sulfate and soil particles, and it has been suggested that the time factor is the most important in the process of leaching sulfate into surface water [11]. Research has shown that the concentration of soluble sulfates in the solution increased their adsorption after an incubation period that lasted for 8 days in the upper horizons of Spodosols. Therefore, increasing the contact rate between soil and sulfate is an important factor for increasing adsorption [13]. Sulfate also depends in its transportation and transformations on the net flux of sulfur(s) flow and on the exchanges that take place within the cycle [14]. The hydrological pools, swamps, and flow paths in the region also play an important role in the sulfate transport process in any ecosystem $[12,15]$. The translocation or leaching and adsorption of sulfate are also affected by the water movement patterns, kinetics and ion exchange[16].

\subsection{Sulfate Adsorption}

Adsorption is the process of accumulating or attracting atoms or molecules of a fluid called the adsorbent on the surface of a solid substance called the absorbate, the adsorption is of two types, either specific or Nonspecific, nonspecific adsorption includes only electrostatic attraction, while specific adsorption occurs through bonding and exchange [17]. Almost all ions are adsorbable indefinitely, but a small class of ions can be adsorbed specifically. Sulfates are compounds that are specifically and nonspecifically adsorbable [18]. It is believed that specific adsorption is the predominant adsorption in the sulfate compound [19]. The process of nonspecific adsorption in sulfates takes place within the double diffuse layer as an ion opposite to the surface on which it is adsorbed, which is positive on the surfaces of most organic materials, silicates, and compounds containing oxides, these materials are often amphoteric and may have a negative, positive or zero charges depending on the $\mathrm{pH}$ [20]. The non-specific adsorption process occurs through the creation of positively charged surfaces through the presence of hydrogen $(\mathrm{H}+)$ ion. When the $\mathrm{pH}$ level decreases, positively charged colloidal surfaces are produced that can attract the anion [21]. The other type of adsorption, which is the determinant, is in which the sulfate adsorption capacity is greater and the fixation of ions between soil molecules is tighter because the adsorption process takes place through chemical bonding and ion exchange. This type of 
adsorption occurs frequently in soils containing iron and aluminium oxides and peroxides [22]. The organic materials and aluminum hydroxy polymers that adhere to the clay also provide surfaces for adsorption of the sulfates [16]. Adsorption can be reversible, partially reversible, or irreversible completely reversible [23]. The adsorption is of three types partially reversible, completely reversible, and completely irreversible desorption the process of determining the type of adsorption that occurs in sulfate depends directly on the type of soil and the amount and type of ions present in the soil in some soils. In some soils, it is fully or partially reversible. "Fig. 1" shows the three types of adsorption [23].

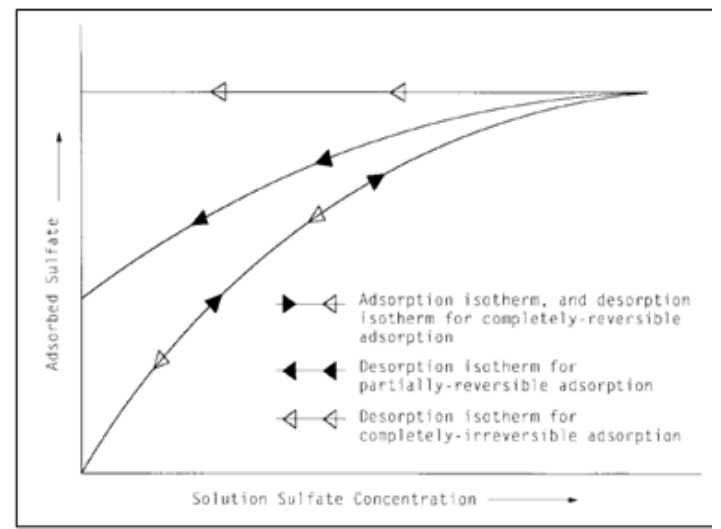

Figure 1. Schematic of adsorption, partially reversible, completely reversible, and completely irreversible desorption isotherms [28].

\subsection{Leaching Losses}

The process of transporting sulfates inside the soil is affected by its concentration in the soil solution and its interaction with the soil contents, as well as the speed and pattern of water movement inside the soil. The atmosphere by acid rain[24-26]. Many experiments have been done on the process of losing or washing the sulfate, and the quantities vary from small to large, reaching 300 kilograms/hectare per year, from these values it is clear that many factors lead to such losses. The following conclusions can be made:

1. The sulfate losses process is greater when monovalent ions such as potassium $(\mathrm{K})$ and sodium $(\mathrm{Na})$ predominate, followed by divalent ions such as calcium $(\mathrm{Ca})$ and magnesium (Mg). Leaching losses are less when the soil is acidic and contains aluminium and iron oxides

2. The amount of sulfate transported from the soil of crops is proportional to the amount of percolated water.

3. When acidic soils, the adsorption of sulfates in them leads to complete and rapid removal of chlorides, thus achieving greater scope for the adsorption process.

4. The presence of lime and phosphates affects the process of losses

5. The Sulfur (S) fertilizer is banded than when broadcasted Thus the sulfate losses are less.

6. losses increase with phosphate amendment or with liming.

Several studies have shown that the physical properties of soil (distribution of soil pore size and surface area) affect the fluid transport process by affecting the velocity gradient, moisture content and diffusion process[27].

\section{Materials and Experimental work}

\subsection{Laboratory model}

A laboratory system for porosity media has been established to study the process of transporting pollutants through porous media and studying the adsorption process and the process of filtering or washing the pollutant. The system consists of 4 transparent tubes made of polyethylene, one tube with a length of 4 meters and a diameter of $8 \mathrm{~cm}$. The pipes are all placed on an iron table with a height of 1.5 meters and the system also contains two tanks, one to transfer the pollutants to the 
pipes, and the second to receive it from the second end, and it also contains a pump. One tube contains 7 holes evenly arranged for each half a meter, the diameter of the hole is $1 \mathrm{~cm}$, and it is equipped with a small tube of $3 \mathrm{~cm}$ to to collect the samples and evaluate the pressures. "Fig. 2" and "Fig. 3" shows the laboratory system.

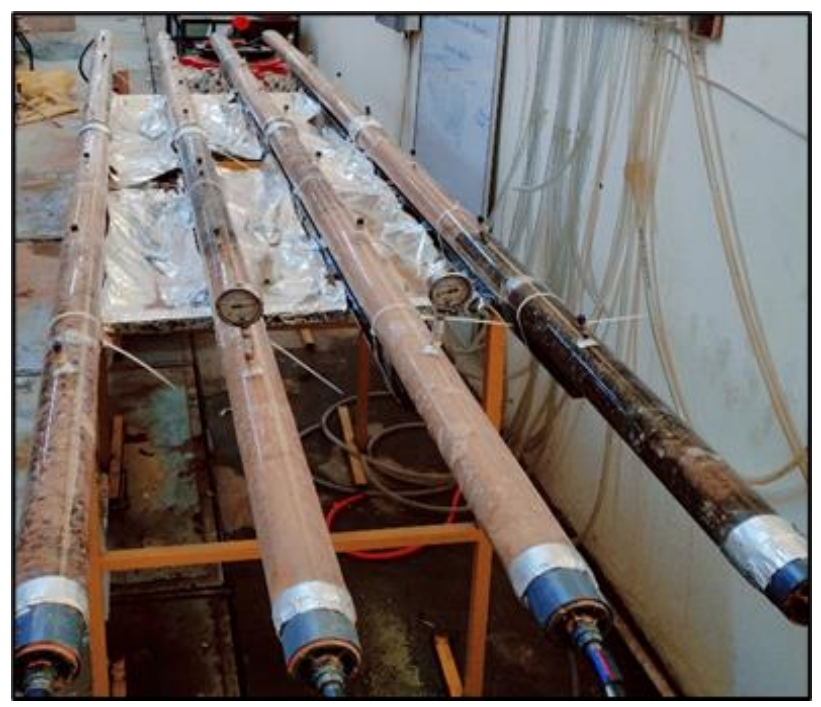

Figure 2. A real laboratory system.

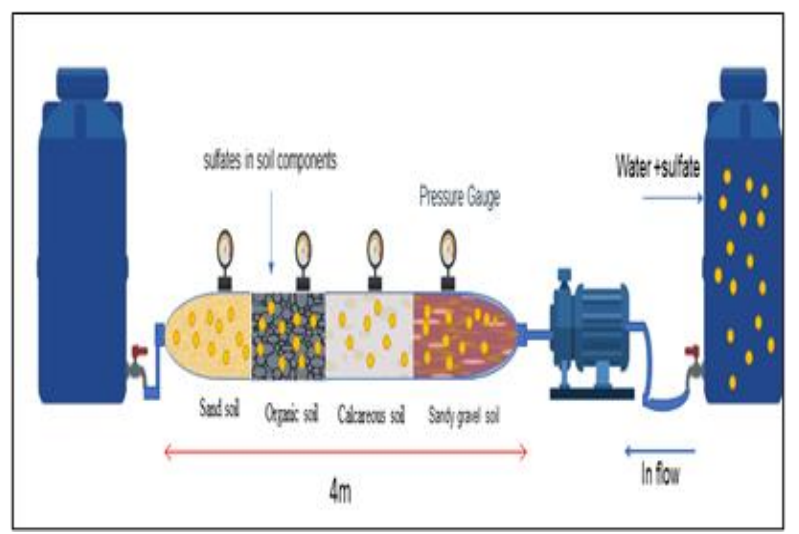

Figure 3. Laboratory system.

\subsection{Porous media}

The porous mediums consist of four types of soil, the first type is sandy soil, which consists of sand with different gradations ranging from $2 \mathrm{~mm}$ to smaller than $0.075 \mathrm{~mm}$. The second type of soil is a sandy gravel soil composed of 60 percent sand and 40 percent gravel. The third type is calcareous soil consisting of 35 percent lime and 65 percent sand, while the fourth type is agricultural soil consisting of a mixture of sand with a ratio of 33.3 , clay and silt with a ratio of 33.3 , and peat moss soil (organic soil) with a ratio of 33.3.

All types of soil have been carried out laboratory tests, which include sieve analysis and examination of real and apparent density, porosity, $\mathrm{pH}$, specific weight and soil sulfate.

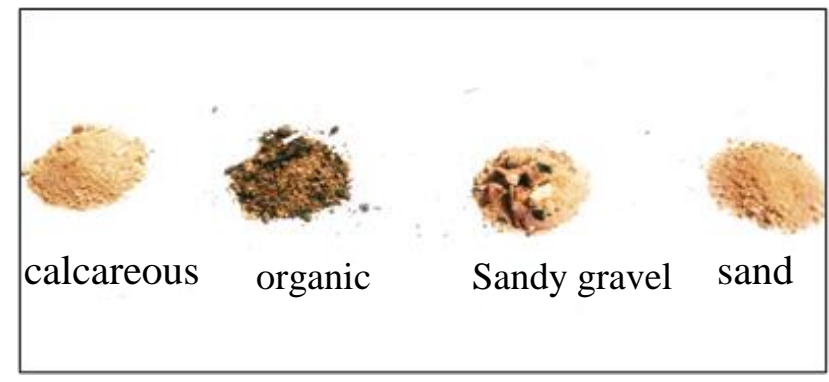

Figure 4. Type of soil use in laboratory model.

\subsection{Soil information used in the experiment}

Table 1. Results experiments of soil.

\begin{tabular}{lllll}
\hline Soil & $\begin{array}{l}\text { Specific } \\
\text { weight }\end{array}$ & porosity & $\begin{array}{l}\text { Bulk } \\
\text { density }\left(\mathbf{g} / \mathbf{c m}^{3}\right)\end{array}$ & PH \\
\hline Sandy & 2.7 & 0.35 & 1.26 & 7.82 \\
Calcareous & 2.94 & 0.29 & 1.37 & 7.92 \\
$\begin{array}{l}\text { Sandy } \\
\text { gravel }\end{array}$ & 2.5 & 0.3 & 1.48 & 7.54 \\
Organic & 1 & 0.22 & 1.02 & 7.19 \\
\hline
\end{tabular}

Table 2. Results sulfate in soil.

\begin{tabular}{lc}
\hline Soil & sulfate in soil $(\mathbf{g} / \mathbf{k g})$ \\
\hline Sandy & 2.06 \\
Calcareous & 10.15 \\
Sandy gravel & 3.63 \\
Organic & 16.95 \\
\hline
\end{tabular}




\section{PERCENT OF SULFATE IN SOIL}

\section{$0.21 \%$}

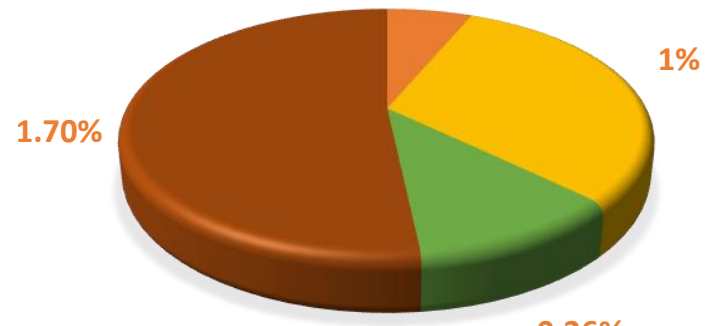

$0.36 \%$

Figure 5. Percent of sulfate in soil.

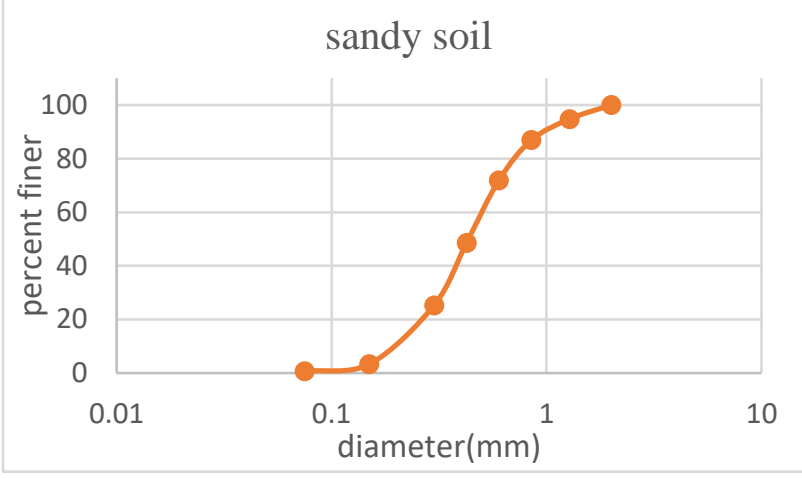

Figure 6. Sieve analysis of sandy soil.

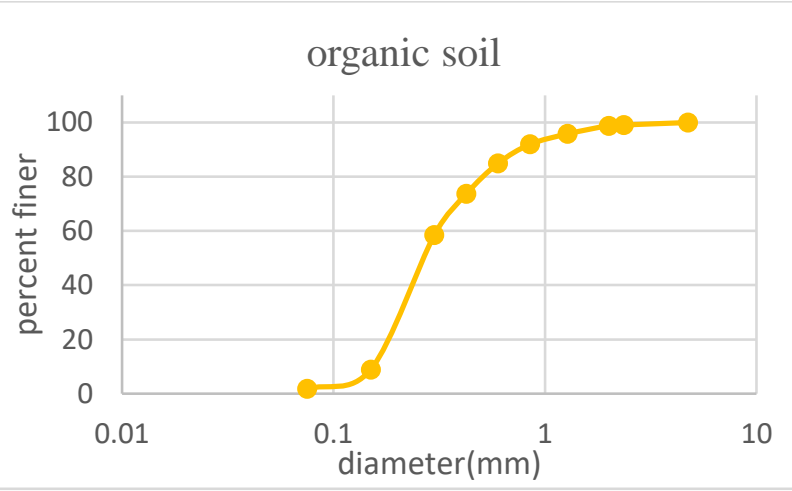

Figure 7. Sieve analysis of organic soil

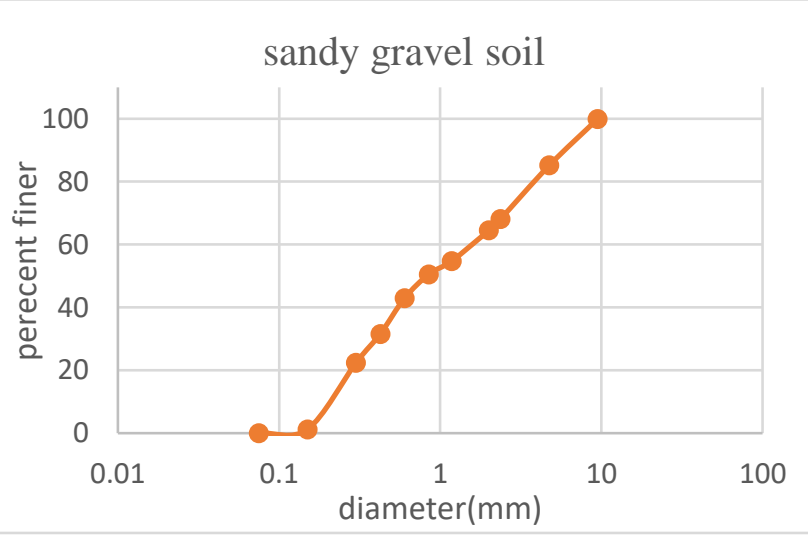

Figure 8. Sieve analysis of sandy grave soil.

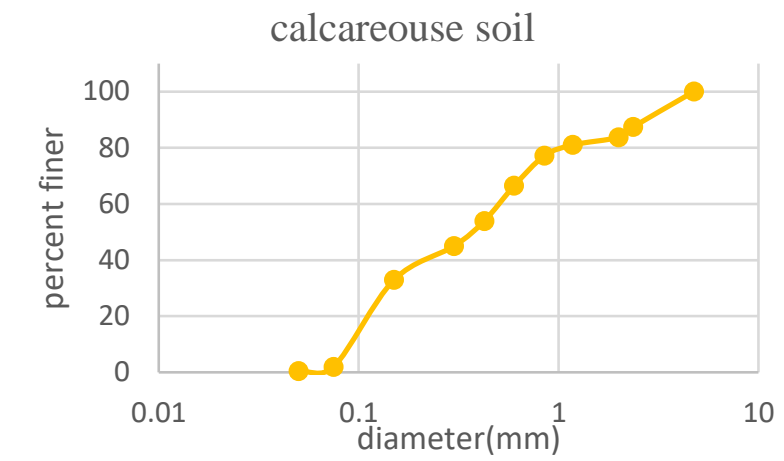

Figure 9. Sieve analysis of sandy grave soil.

\subsection{Experimental work}

In this work, firstly the soil was filled in the tube and the soil was stacked inside the tube to get rid of the voids as shown in "Fig. 3". The soil in the tube was arranged so that the first meter of the tube includes sandy gravel soil, the second meter of calcareous soil, and the third meter agricultural soil, while the fourth and last meter filled with sandy soil. Then, the pollutant was prepared in a tank by adding sodium sulfate and magnesium sulfate to drinking water with a capacity of 250 litres, which also contains a certain percentage of sulfates that was taken into account. After the addition, the water was stirred using a mixer and mixed well for five minutes in order to form a homogenous mixtureand the concentration was the output is $280 \mathrm{mg} / 1(2.92 \mathrm{mmol} / \mathrm{l})$. After the completion of the process, a measured quantity of the pollutant is pumped into the tube that contains the soil through the pump, and the amount of outflow from it is equal to 30 liters / minute and the amount of outflow from the last point of the tube after passing through all the soil is 0.0538 liters / minute.

\section{Results and Discussion}

\subsection{Results of Porosity}

Porosity can be defined as the amount or size of the spaces between the soil particles. Porosity has been measured in this paper for all existing soil types and its importance in the washing process 
or the loss of sulfates from the soil or even the effect on the adsorption process. Water or soil solution through soil particles, as the porosity increases, the speed of water flow increases, and thus this affects the process of sulfate loss from the soil, i.e. the flow of water through the soil will be larger and faster, while on the contrary, when the porosity is low, the speed of water becomes slower and thus the process of bonding time between Water and soil particles become larger, and thus the possibility of adsorption between the pollutant and the soil is greater than the pollutant loss process.

\subsection{Results Laboratory Experiments}

After the process of pumping water with sulphates in the multiple soils that also contain the same pollutant, which lasted for hours, the results of the samples that were pulled from the eight points located along the tube "Fig. 10" after half an hour after the pumping process showed that the washing process or the loss of sulfates from the soil It is the effective process more than the adsorption process, as the washing started from the first meter containing the sandy gravel soil and then extended to the second meter containing the calcareous soil, in which we observe the most rate of loss and this is due to the porosity and to the nature of the soil which is of reversible adsorption, after that The water enters the third meter containing organic soil, which we note the adsorption process is the most active process, although the soil contains the most amount of sulfates that it is capable of adsorption and this is due to the low porosity and also the nature of the soil and its containment of a variety of ions capable of adsorption effectively, and after This enters the water into the fourth meter containing the sandy soil and also returns again. The process of loss or washing is the most active.

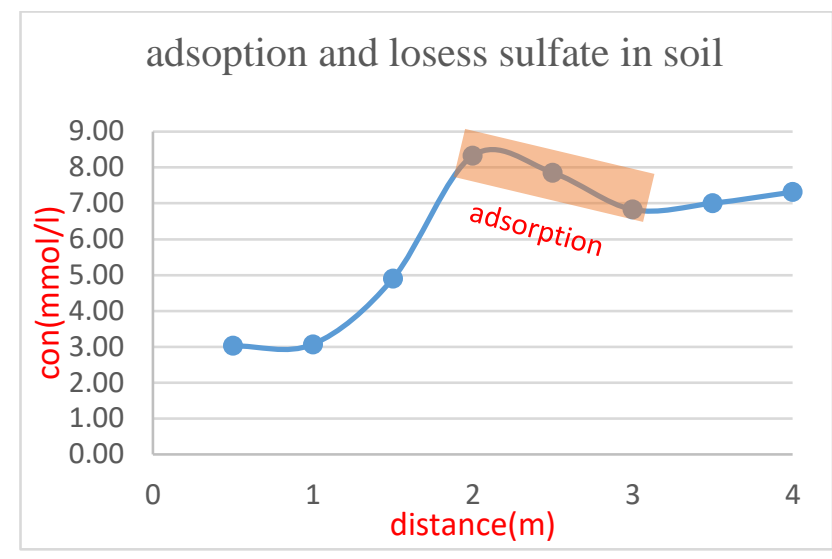

Figure 10. Adsorption and loss sulfate in soil after 30 minuets.

After the process of pumping water with sulphates in the multiple soils that also contain the same pollutant, which lasted for hours, the results of the samples that were withdrawn from the eight points located along the tube "Fig. 11 "half an hour after the pumping process showed that the washing process or the loss of sulfates from the soil It is the effective process more than the adsorption process, as the washing started from the first meter containing the sandy gravel soil and then extended to the second meter containing the calcareous soil, in which we observe the most rate of loss and this is due to the porosity and to the nature of the soil which is of retroactive adsorption, after that The water enters the third meter containing organic soil, which we note the adsorption process is the most active process, although the soil contains the most amount of sulfates that it is capable of adsorption and this is due to the low porosity and also the nature of the soil and its containment of a variety of ions capable of adsorption effectively, and after This enters the water into the fourth meter containing the sandy soil and also returns again the process of loss or washing, which is the most active process. "Fig12".

After that, the process was left for about three days without pumping, and on the third day, odours were observed from the organic soil due to the process of sulfate reduction by bacteria 
which gives off hydrogen sulfide gas according to the following equation:

$\mathrm{SO}_{4}^{-2}+\mathrm{ATp}^{-4} \longrightarrow \mathrm{APS}^{2-}+\mathrm{PPj}^{4-}[28]$. $\mathrm{APS}^{2-}+\mathrm{MKH}^{2} \longrightarrow \mathrm{SO}_{3}{ }^{2-}+\mathrm{MK}+\mathrm{AMp}^{2-}+$ $2 \mathrm{H}^{+}[28]$.

$\mathrm{SO}_{3}{ }^{2-}+6[\mathrm{H}]+2 \mathrm{H}^{+} \longrightarrow \mathrm{H}_{2} \mathrm{~S}+3 \mathrm{H}_{2} \mathrm{O}[29]$.

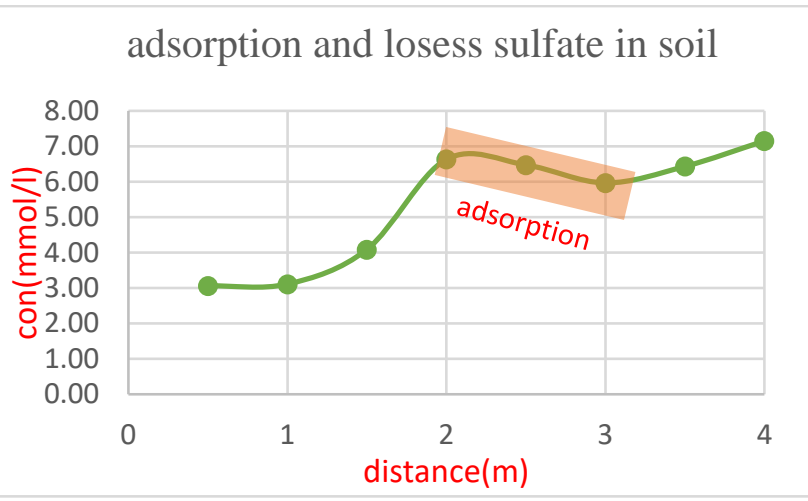

Figure 11. Adsorption and loss sulfate in soil after 60 minuets.

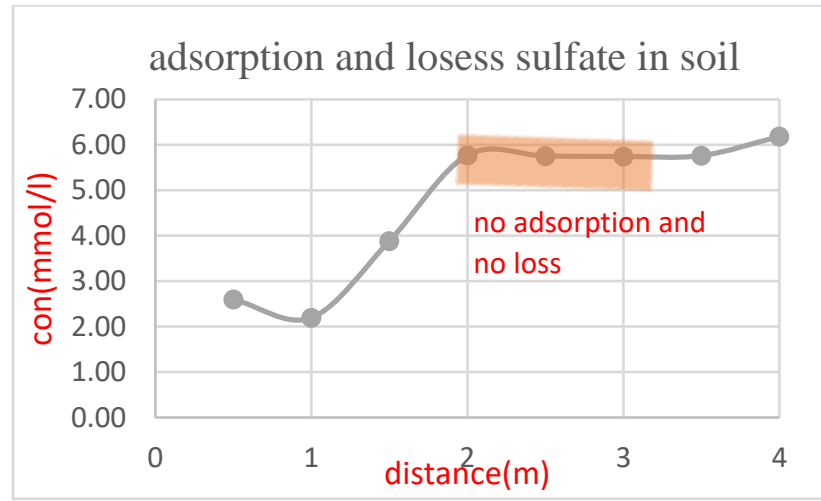

Figure 12. Adsorption and loss sulfate in soil after 120 minuets.

adsorption and losess sulfate in soil

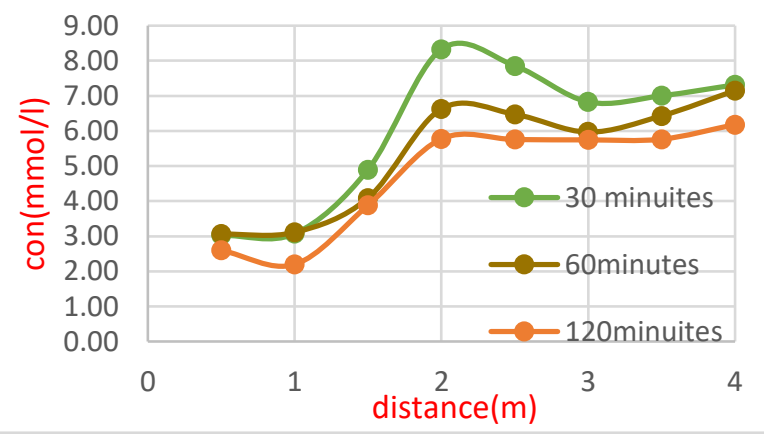

Figure 13. Adsorption and loss sulfate in soil after 120 minuets.

\section{Conclusions}

Through the apparent results, it was found that organic soils with irreversible adsorption, unlike the rest of the soils, are capable of adsorption more than the rest, but this does not mean that pollutants, especially sulfates, cannot be transferred from one soil to another. Bacteria have a major role in the sulfate disposal process, and this opens an opportunity for developing soils to get rid of sulfates or salts. It is preferable to take pumping operations for a longer time to learn to obtain greater results to facilitate the process of understanding the flow of sulfate pollutants through the porous media in the soil.

\section{Conflict of Interest}

The authors declare that there are no conflicts of interest regarding the publication of this manuscript.

\section{References}

1. AL-Daood, A. A. (2011). "A study of contaminate through layered soil due to leachate migration from landfill site", AlRafidain Eng. J., 19, (4), 28-42.

2. Kattab, A. A., AL-Daood, A. A. and Khalil, A. A. (2010). "Range of contaminate transport in soil under saturated/unsaturated condi- tions with case study", Al Rafidain Eng. J., 18, (2), 50-71.

3. Erdem, H., Torun, M. B., Erdem, N., Tolay, İ., Günal, E., \& Özkutlu, F. (2016). "Effects of different forms and doses of sulphur application on wheat". Turkish Journal of Agriculture-Food Science and Technology, 4(11), 957-961.

4. Wilhelm Scherer, H. (2009). "Sulfur in soils. Journal of Plant Nutrition and Soil Science", 172(3), 326-335.

5. Mascagni Jr, H. J., Harrison, S. A., \& Padgett, G. B. (2008). "Influence of sulfur fertility on wheat yield performance on 
alluvial and upland soils". Communications in soil science and plant analysis", 39(13-14), 2133-2145.

6. Sadiq, S. M., Gubashi, K. R., Chyad R. F., \& Al-Sharify, Z. T. (2018). "Removal of Inorganic Contaminants Using Manufacturing Porous Media". International Journal of Engineering \& Technology, 7(4), 142-145.

7. Barber, S. A. (1995). "Soil Nutrient Availability". A Mechanistic Approach. 2nd edn., John Wiley \& Sons, Inc., New York.

8. Barrow, N. J. (1975). "Reactions of fertiliser sulphate in soil", in McLa- chlan, K. D. (ed.): Sulphur in Australian Agriculture. Sydney University Press, Sydney, pp. 50-57.

9. Gregg, P. E. H., Goh, K. M. (1978). "Field studies with radioactive sulfur-labelled gypsum fertilizer". I. Soil factors affecting the movement of fertilizer sulfur. N. Z. J. Agric. Res. 21, 593-601.

10. Chao, T. T., Harward, M. E., Fang, S. C. (1962): "Adsorption and desorption phenomena of sulfate ions in soils". Soil Sci. Soc. Am. Proc. 26, 234-237.

11. Vance, G. F.; David, M. B. 1992. "Dissolved organic carbon and sulfate sorption by Spodosol mineral horizons". Soil Science. 154:136-144.

12. Randlett, D. L.; Zak, D. R.; MacDonald, N. W. (1992). "Sulfate adsorption and microbial immobilization in northern hardwood forests along an atmospheric deposition gradient". Canadian Journal of Forest Research. 22:1843-1850.

13. Landers, D. H., \& Mitchell, M. J. (1988). "Incorporation of $35 \mathrm{SO}_{4}{ }^{2-}$ into sediments of three New York lakes". Hydrobiologia, 160(1), 85-95.

14. Schnabel, R. R.; Potter, R. M.; Ritchie, E. B. (1991). "Applying batch-determined retention properties to predict sulfate transport through soil columns". Soil Science. 152:440-447.

15. Johnson, D. W.; Henderson, G. S. (1979). "Sulfate adsorption and sulfur fractions in a highly weathered soil under a mixed deciduous forest". Soil Science. 128:34-40.

16. Harward, M. E.; Reisenauer, H. M. (1966). "Reactions and movement of inorganic soil sulfur. Soil Science". 101:326-335.

17. Parfitt, R. L.; Smart, R. St.C. (1978). "The mechanism of sulfate adsorption on iron oxides". Soil Science Society.

18. Johnson, D. W.; Cole, D. W.; Gessel, S. P. (1979b). "Acid precipitation and soil sulfate adsorption properties in in a temperate forest soil". Biotropica.11:38-42.

19. "Neary, A. J.; Mistry, E.; Vanderstar, L. (1987). "Sulphate relationships in some central Ontario forest soils.Canadian Journal Soil Science". 67:341-352.

20. Bohn, H. L., \& McNeal, B. L.McNeal. (1983)."A qualitative derivation of the diffuse double layer." Journal of Agronomic Education 12.1: 26-28.

21. Johnson, D. W.; Cole, D.W. (1980). "Anion mobility in soils:relevance to nutrient transport from forest ecosystems. Environment International". 3:79-90.

22. Fuller, R. D.; David, M. B.; Driscoll, C. T. (1985). "Sulfate adsorption relationships in forested Spodosols of the northeastern USA". Soil Science Society of America Journal. 49:1034-1040.

23. Landers, D. H., \& Mitchell, M. J. (1988). "Incorporation of $35 \mathrm{SO}_{4}{ }^{2-}$ into sediments of three New York lakes". Hydrobiologia, 160(1), 85-95.

24. J. S. Joffe, "Lysimeter studies: II"," Soil Sci. 35: 239 (1933).

25. Dreibelbis, F. R. (1947). "Some plant nutrient losses in gravitational water from monolith lysimeters at Coshocton, Ohio". 
Soil Science Society of America Journal, 11(C), 182-188.

26. Sollins, P., Grier, C. C., McCorison, F. M., Cromack Jr, K., Fogel, R., \& Fredriksen, R. L. (1980). "The internal element cycles of an old-growth Douglas-fir ecosystem in western Oregon". Ecological monographs, 50(3), 261-285.

27. Reuss, J. O., \& Johnson, D. W. (2012). "Acid deposition and the acidification of soils and waters (Vol. 59) ". Springer Science \& Business Media.

28. ohnson, D. W., Breuer, D. W., \& Cole, D. W. (1979). "The Influence of Anion Mobility on Ionic Retention in Waste Water-irrigated Soils" (Vol. 8, No. 2, pp. 246-250). American Society of Agronomy, Crop Science Society of America, and Soil Science Society of America.

29. Kunow, j., Linder, D., Stetter, K. 0., and Thauer, R. K., (1994a), "F420H2:quinone oxidoreductase from Archaeoglobus fulgidus: characterization of a membrane bound multisubunit complex containing FAD and iron-sulfur clusters". Eur.J. Biochem. 233:503-511. 